\title{
Research on teaching evaluation strategies of mechanical and electrical professional English teachers based on Analytic Hierarchy Process
}

\author{
Jian Yong 1,a \\ Weihai Vocational College, Shandong, China \\ 1541545319@qq.com
}

\begin{abstract}
Key words: Analytic hierarchy process; Mechanical and electrical English teachers; Teaching Ability ; Evaluation; AHP

Abstract: With the rapid development of social economy, mechanical and electrical professional graduates play an increasingly important role in society. It is an important subject in front of us that how to cultivate high quality electromechanical graduates. The comprehensive quality of mechanical and electrical English teachers is related to the quality of students' training. While the electromechanical class English teachers' comprehensive quality is uneven. This paper based on hierarchical analysis method, starts with how to improve the comprehensive quality of electromechanical English teachers, carries on the empirical study of electromechanical Specialty English teachers teaching evaluation strategy, in order to improve our teaching quality play the role of attracting valuable opinions.
\end{abstract}

\section{Introduction}

With the rapid development of social economy, the major setting of higher education institutions is becoming more and more standardized. What' s more, mechanical and electrical profession as a pillar of professional colleges and universities is particularly prominent. The comprehensive quality of mechanical and electrical English teachers is related to the quality of training students. It is an important subject that how to cultivate high quality electromechanical graduates in front of us. At present, the mechanical and electrical class English teachers' comprehensive quality is uneven. In teaching, the existing problems are that either college English teachers lack mechanical and electrical professional theory and practice knowledge when they teach professional courses, or mechanical and electrical class teachers have problems in English foundation such as pronunciation, syntactical structure and textual structures . This paper is based on hierarchical analysis method, starts with how to improve the comprehensive quality of electromechanical English teachers, carries on the empirical study of Electromechanical Specialty English teachers teaching evaluation strategy, in order to improve our teaching quality to play the role of attracting valuable opinions.

\section{Evaluation index system}

1)Research objects: This paper adopts questionnaire method, taking full-time vocational college students, mechanical \& electrical engineering enterprises and College English teachers as the research objects, We establish the frame system, from the five aspects of professional knowledge: English level, practical skills, teaching ability and Growth momentum.

2)The principle of establishing teaching evaluation index system: We establish the framework system according to the basic requirements of human resource evaluation methods and the principle of overall quality, serving the society, people-oriented, overall development, qualitative and quantitative combination, for the mechanical and electrical professional English teachers on the five aspects of the professional knowledge: English proficiency, practical skills, teaching ability, and the growth momentum.

3) Composition and weight of teaching evaluation index system

Professional knowledge; English level: Practical skills: Growth momentum.

Each level index is divided into four to five different two level indexes and determines the weight of the two level indexes. 


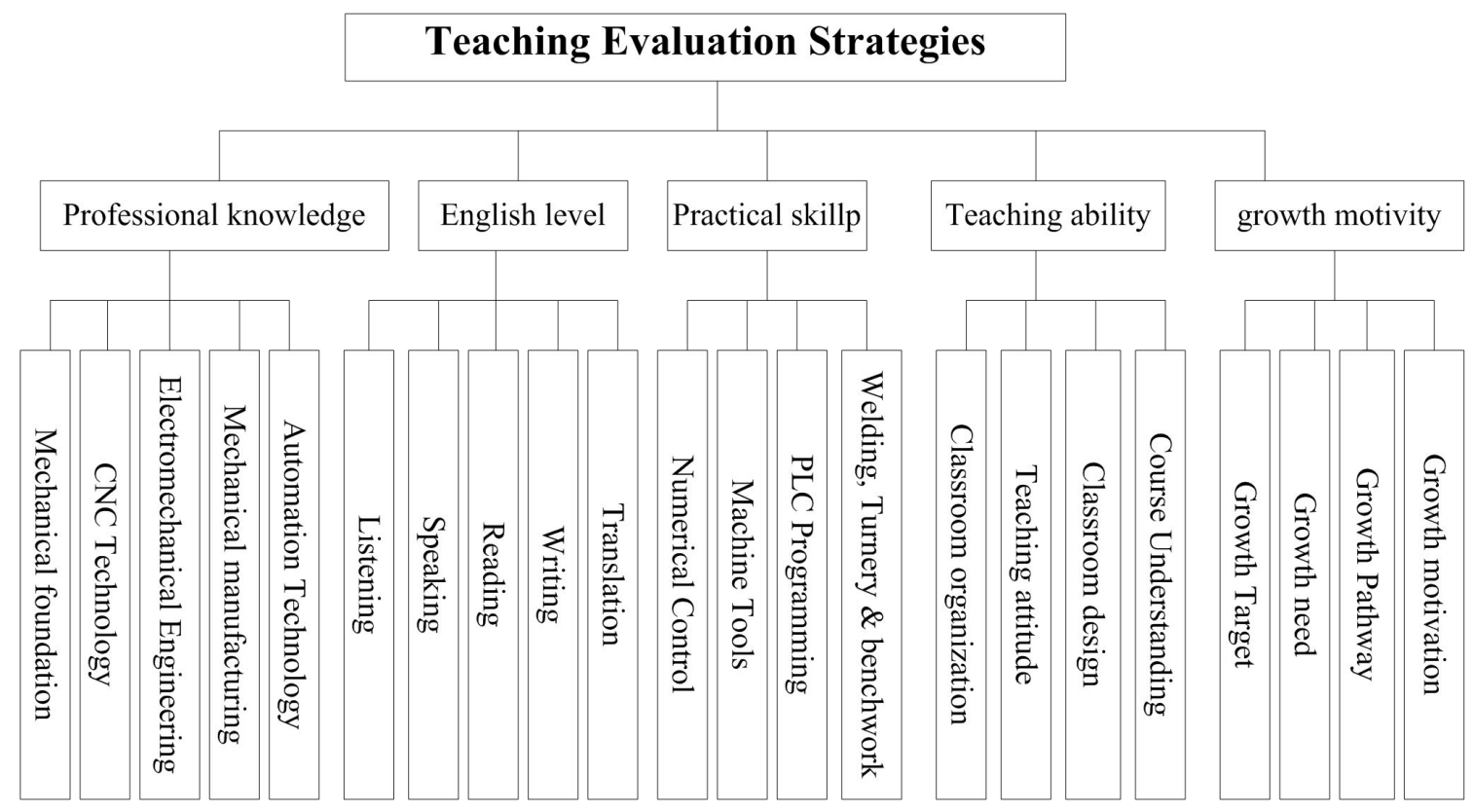

Fig. 1 Teaching Evaluation Strategies

\section{Construction of evaluation index system}

Judgment matrix means that each index of the matrix reflects the degree of impact on various influencing factors of the same level of the upper index size, and use quantitative methods to compare the importance of each index in the same level, and get the final outcome, and place the position in the matrix corresponding to Calculation index weight value.

Calculate index weight value

$W=W\left(W_{1}, W_{2}, \cdots, W_{n}\right)^{T}$

It can be obtained by solving the following equation $W$ :

$A W=\lambda_{\max } W$

And the accurate value of each index weight can be obtained through the following calculation process,

$M_{i}=\prod_{j=1}^{n} a_{i j}(i, j=1,2, \cdots, n)$

Caculate $\bar{W}_{i}$, n root mean square $M_{i}$ :

$\bar{W}_{i}=\sqrt[n]{M_{i}}$

The vetor normalize processing $\bar{W}=\left(\bar{W}_{1}, \bar{W}_{2}, \cdots, \bar{W}_{n}\right)^{\mathrm{T}}$

$W_{i}=\bar{W}_{i} / \sum_{i=1}^{n} \bar{W}_{j}(i, j=1,2, \cdots, n)$

Calculate $\lambda_{\max }$, the maximum eigenvalue of the matrix A:

$\lambda_{\max }=\frac{1}{n} \sum_{\mathrm{i}=1}^{n}(A W)_{i} / W_{i}$

(4) Test consistency

$C I=\frac{\lambda_{\max }-n}{n-1}$ 


$$
C R=\frac{C I}{R I}
$$

\section{Setup Judgment Matrices}

The hierarchical structure of this paper is based on the evaluation index system of the crew's quality under the emergency conditions established above, and test the consistency, and weigh the value of each index layer as follow:

$\left[\begin{array}{lllll}1 & 2 & 5 & 4 & 7 \\ 1 / 2 & 1 & 3 & 2 & 4 \\ 1 / 5 & 1 / 3 & 1 & 1 / 2 & 2 \\ 1 / 4 & 1 / 2 & 2 & 1 & 3 \\ 1 / 7 & 1 / 4 & 1 / 2 & 1 / 3 & 1\end{array}\right]$

$\mathrm{W}=\left(\begin{array}{lllll}0.4666 & 0.2485 & 0.0880 & 0.11427 & 0.0543\end{array}\right)$

$\lambda_{\max }=5.0475$

$\left[\begin{array}{ccccc}1 & 1 / 3 & 1 / 7 & 1 / 2 & 1 / 3 \\ 3 & 1 & 1 / 3 & 2 & 1 / 3 \\ 7 & 3 & 1 & 5 & 2 \\ 2 & 1 / 3 & 1 / 5 & 1 & 1 / 3 \\ 3 & 3 & 1 / 2 & 3 & 1\end{array}\right]$

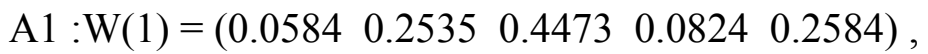

$\mathrm{A} 1: \lambda \max =5.1813, \mathrm{CI}=0.0453, \mathrm{CR}=0.04047<0.1$

$\left[\begin{array}{ccccc}1 & 1 / 3 & 1 / 3 & 1 / 5 & 1 / 7 \\ 3 & 1 & 1 / 3 & 1 / 4 & 1 / 7 \\ 3 & 3 & 1 & 1 / 2 & 1 / 3 \\ 5 & 4 & 2 & 1 & 1 / 2 \\ 7 & 7 & 3 & 2 & 1\end{array}\right]$

$\mathrm{A} 2: \mathrm{W}(2)=\left(\begin{array}{lllll}0.0462 & 0.0750 & 0.1583 & 0.2657 & 0.4549\end{array}\right)$,

$\mathrm{A} 2: \lambda \max =5.1522, \mathrm{CI}=0.03806, \mathrm{CR}=0.03398<0.1$

$\left[\begin{array}{llll}1 & 3 & 5 & 7 \\ 1 / 3 & 1 & 4 & 4 \\ 1 / 5 & 1 / 4 & 1 & 3 \\ 1 / 7 & 1 / 4 & 1 / 3 & 1\end{array}\right]$ 
A3: $\mathrm{W}(3)=\left(\begin{array}{llll}0.5642 & 0.2679 & 0.1097 & 0.0582\end{array}\right)$,

A3: $\lambda \max =4.1806, C I=0.0602, C R=0.06689<0.1$

According to the same principle, we get the following conclusion:

A4: $\mathrm{W}(4)=\left(\begin{array}{llll}0.1015 & 0.0539 & 0.2929 & 0.5518\end{array}\right)$

$\mathrm{A} 4: \lambda \max =4.2278, \mathrm{CI}=0.07593, \mathrm{CR}=0.08437<0.1$

A5: $\mathrm{W}(5)=\left(\begin{array}{llll}0.0769 & 0.4452 & 0.1331 & 0.3448\end{array}\right)$

A5: $\lambda \max =4.1866, \mathrm{CI}=0.0622, \mathrm{CR}=0.06911<0.1$

\section{Conclusion}

From the above analysis, we can draw the following conclusions: In comprehensive quality of mechanical and electrical professional English teachers, the second level indicators include professional knowledge, English level, practical skills, teaching ability and growth momentum. In all the indicators professional knowledge, occupies first place, because only the teachers understand professional knowledge, they can explain professional English clearly. English level is a second, as a professional English teacher, they must have solid basic skills. In addition, electrical and mechanical English teachers are also required to have the practical skills. Relatively speaking, teaching ability, growth momentum is not particularly important.

In the three level indicators, professional knowledge includes the application of mechanical and electrical engineering, mechanical and electrical engineering, mechanical manufacturing, mechanical automation, etc;

In listening, speaking, reading and writing in English, translation and writing are the main positions, while the ability of listening and speaking are not important.

Practical skills includes CNC, machine tools, electric welding, PLC programming, Turner, fitter, and, in these factors, $\mathrm{CNC}$ machine tools are important..

The teaching ability includes the teaching organization, the teaching manner, the teaching design and the curriculum understanding and so on. The course understanding factor is in the first place. Growth momentum including growth target, growth demand, growth path, growth motivation, growth demand is the most important influence factor.

\section{References}

[1] Discretion and bias in performance evaluation: the impact ofdiversity and subjectivity Volume [ J ] :30, Issue: 1, January, 2005,pp.67-78

[2] http://thequalityportal.com/q_ahp.htm. Retrieved 2007-08-21.

[3] European Management Journal Volume [ J ] :21, Issue:3, June, 2003. pp323-337 